\title{
Regulation of Dendritic Branching and Spine Maturation by Semaphorin3A-Fyn Signaling
}

\author{
Asa Morita, ${ }^{1}$ Naoya Yamashita, ${ }^{1}$ Yukio Sasaki, ${ }^{1}$ Yutaka Uchida, ${ }^{1}$ Oumi Nakajima, ${ }^{1}$ Fumio Nakamura, ${ }^{1}$ Takeshi Yagi, ${ }^{3}$ \\ Masahiko Taniguchi, ${ }^{4}$ Hiroshi Usui, ${ }^{1}$ Ritsuko Katoh-Semba, ${ }^{5}$ Kohtaro Takei, ${ }^{1,2}$ and Yoshio Goshima ${ }^{1,2}$ \\ ${ }^{1}$ Department of Molecular Pharmacology and Neurobiology, Yokohama City University Graduate School of Medicine, Yokohama 236-0004, Japan, ${ }^{2}$ Core \\ Research for Evolutional Science and Technology, Japan Science and Technology Agency, Kawaguchi 332-0012, Japan, ${ }^{3}$ KOKORO-Biology Group, \\ Laboratories for Integrated Biology, Graduate School of Frontier Biosciences, Osaka University, Suita 565-0871, Japan, ${ }^{4}$ Department of Biochemistry and \\ Molecular Biology Graduate School of Medicine, University of Tokyo, Tokyo 113-0033, Japan, and 5 Institute for Developmental Research, Aichi Human \\ Service Center, Aichi 480-0392, Japan
}

A member of semaphorin family, semaphorin3A (Sema3A), acts as a chemorepellent or chemoattractant on a wide variety of axons and dendrites in the development of the nervous systems. We here show that Sema3A induces clustering of both postsynaptic density-95 (PSD-95) and presynaptic synapsin I in cultured cortical neurons without changing the density of spines or filopodia. Neuropilin-1 (NRP-1), a receptor for Sema3A, is present on both axons and dendrites. When the cultured neurons are exposed to Sema3A, the cluster size of PSD-95 is markedly enhanced, and an extensive colocalization of PSD-95 and NRP-1 or actin-rich protrusion is seen. The effects of Sema3A on spine morphology are blocked by PP2, an Src type tyrosine kinase inhibitor, but not by the PP3, the inactive-related compound. In the cultured cortical neurons from $f \mathrm{yn}^{-/-}$mice, dendrites bear few spines, and Sema3A does not induce PSD-95 cluster formation on the dendrites. Sema3A and its receptor genes are highly expressed during the synaptogenic period of postnatal days 10 and 15. The cortical neurons in layer V, but not layer III, show a lowered density of synaptic bouton-like structure on dendrites in sema3A-and fyn-deficient mice. The neurons of the double-heterozygous mice show the lowered spine density, whereas those of single heterozygous mice show similar levels of the spine density as the wild type. These findings suggest that the Sema3A signaling pathway plays an important role in the regulation of dendritic spine maturation in the cerebral cortex neurons.

Key words: Sema3A; Fyn; dendrite; spine; cerebral cortex; axon guidance

\section{Introduction}

The dendritic architecture of a neuron determines the nature of its inputs and its role in neural circuitry. These processes begin to form during embryogenesis but continue to extend and branch profusely long after neuronal migration is complete, contributing significantly to postnatal neural development. A large body of evidence indicates that dendritic development initially follows genetic dictates but can be modified by extrinsic cues such as neuronal activity and the neurotrophin family of growth factors (Kang and Schuman, 1996; Horch et al., 1999; Li et al., 2002; Vaillant et al., 2002; Hua and Smith, 2004).

Semaphorins, a large family of guidance cues for axonal/dendritic projections, are both secreting and membrane-bound proteins sharing a Sema domain. The class 3 subfamily of the eight

Received April 30, 2005; revised Jan. 27, 2006; accepted Jan. 27, 2006.

This work was supported by the Core Research for Evolutional Science and Technology of Japan Science and Technology Agency (K.T., Y.G.) and by the Yokohama Medical Foundation (Y.G.). We thank Dr. H. Fujisawa for his generous gift of anti-NRP-1 antibody. We thank Dr. S. Okabe for helpful discussion and constructive inputs. We also thank Y. Sugiyama, T. Gotoh, S. Yanai, and C. Imaizumi for technical assistance.

Correspondence should be addressed to Yoshio Goshima, Department of Molecular Pharmacology and Neurobiology, Yokohama City University, School of Medicine, Fuku-ura 3-9, Kanazawa Ward, Yokohama City 236-0004, Japan.E-mail: goshima@med.yokohama-cu.ac.jp.

Y. Sasaki's present address: Department of Cell Biology, Emory University School of Medicine, Atlanta, GA 30322. D01:10.1523/JNEUROSCI.5453-05.2006

Copyright $\odot 2006$ Society for Neuroscience $\quad$ 0270-6474/06/262971-10\$15.00/0 semaphorin subfamilies, composed of at least seven known members, has been the best characterized subfamily. These semaphorins are secreted molecules that function as chemorepulsive/ attractive cues in various neuronal and non-neuronal culture systems (Raper, 2000; Pasterkamp and Kolodkin, 2003; Fujisawa, 2004). Class 3 semaphorins, including semaphorin 3 A (Sema3A), promote a variety of cellular responses, including cytoskeletal reorganization, endocytosis, and facilitation of axonal transport (Nakamura et al., 2000; Goshima et al., 2002; Huber et al., 2003; Li et al., 2004). Class 3 semaphorins have also been implicated in tissue morphogenesis (Kagoshima et al., 2001; Serini et al., 2003) and regulation of dendritic patterning in cortical neurons (Polleux et al., 2000; Sasaki et al., 2002; Fenstermaker et al., 2004; Sahay et al., 2005). The semaphorin receptors that mediate class 3 semaphorin signal has been identified as a complex of neuropilins and plexins. Neuropilin (NRP)-1 and -2 bind to class 3 semaphorins with high affinities, and NRP-1 is necessary for Sema3Amediated repulsive guidance events (Raper, 2000; Pasterkamp and Kolodkin, 2003; Fujisawa, 2004). NRPs and plexin-As are ligand-binding and signal-transducing subunits of class 3 semaphorin receptor complexes, respectively (Takahashi et al., 1999; Tamagnone et al., 1999). Although how Sema3A regulates cytoskeletal dynamics remains obscure, several intracellular molecules, including the small GTPase Rac1, R-Ras, the collapsin 
(Sema3A) response mediator protein (CRMP), LIM (Lin-11, Isl-1, and Mec-3) kinase, and FARP2 (FMRFamide-related peptide-2) have been implicated as mediators of Sema3A signaling (Nakamura et al., 2000; Aizawa et al., 2001; Goshima et al., 2002; Huber et al., 2003; Oinuma et al., 2004; Toyofuku et al., 2005). We demonstrated previously that the Fyn-cyclindependent kinase 5 (Cdk5) complex acts as a downstream mediator of Sema3A signaling cascades that induce growth cone collapse, and sequential phosphorylation of CRMP2 by Cdk5 and glycogen synthase kinase $3 \beta$ plays a critical role in mediating the response (Sasaki et al., 2002; Uchida et al., 2005).

In the present study, we investigated the effects of Sema3A on dendrite and spine morphogenesis in the cultured cortical neurons. We further studied spine morphology of the cerebral cortex neurons in sema3A- and fyn-deficient mice using Golgiimpregnation analysis. We here propose that, in addition to its role as a guidance cue for axonal/dendritic projections, Sema3A plays a role in defining neural connectivity in the CNS.

\section{Materials and Methods}

Materials. 4-Amino-5-(4-chlorophenyl)-7-(tbutyl)pyrazolo[3,4-d]pyrimidine (PP2) and 4-amino-7-phenylpyrazol[3,4-d]pyrimidine (PP3) were purchased from Calbiochem (La Jolla, CA). Lavendustin A was from Wako Chemicals (Osaka, Japan). Poly-L-lysine and L-glutamine were from Sigma (St. Louis, MO). Neurobasal medium and B27 were from Invitrogen (Cergy Pontoise, France). Double staining with 4',6diamidino-2-phenylindole (DAPI) (Sigma) and anti-microtubuleassociated protein 2 (MAP2) antibody [monoclonal antibody (mAb); Sigma] was used for assessing the percentage of cells with neurites and dendritic branching in cultured neurons. Other antibodies used were anti-postsynaptic density-95 (PSD-95) [mAb; Upstate (Charlottesville, VA), Sigma, and Affinity BioReagents (Golden, CO)], synapsin I (Chemicon, Temecula, CA), and rhodamine-labeled phalloidin, Alexa Fluor 594-labeled goat anti-mouse, and Alexa Fluor 488-labeled goat anti-rabbit antibodies (Invitrogen, Carlsbad, CA). Anti-NRP-1 antibody was provided by Dr. H. Fujisawa (Nagoya University, Nagoya, Japan). Recombinant Sema3A was prepared as described previously (Goshima et al., 1997).

fyn and sema3A mutant mice. Genotypes of the offspring of fyn- and sema3A-deficient mice were assessed using PCR as described previously (Sasaki et al., 2002). Mice were housed in the standard mouse facility and fed with autoclaved diet and water. All procedures were performed according to the guideline outlined in the institutional Animal Care and Use Committee of the Yokohama City University School of Medicine. Throughout the experimental procedures, all efforts were made to minimize the number of animals used and their suffering.

Primary cortical culture. Cortical neurons derived from embryonic day 16.5 (E16.5) brains of ICR mice were plated on four-well dishes (Nalgen, Rochester, NY) coated with poly-L-lysine (Sigma) at a density of $4-7 \times$ $10^{4}$ cells per well and grown in Neurobasal medium supplemented with B27 and L-glutamine. Neurons were fixed for immunostaining at 1, 7, or $14 \mathrm{~d}$ after plating for estimation of the Sema3A effects on neurite outgrowth, branching, and spine maturation, respectively. Sema3A, when treated, was applied to the cultured neurons for $24 \mathrm{~h}$ before the fixation. To estimate effects of Sema3A, spines with bouton-like structure and neurites longer than $20 \mu \mathrm{m}$ of the cultured cortical neurons on plastic coverslips (Nalgen) were traced and counted. Lavendustin A, PP2, or PP3 when tested was applied to the culture $30 \mathrm{~min}$ before application of Sema3A.

Quantification of neurotrophin-3 and brain-derived neurotrophic factor. The conditioned medium and the extracts of the cultured cells with and without Sema3A treatment were used for quantification of brain-derived neurotrophic factor (BDNF) and neurotrophin-3 (NT-3) using a highly sensitive enzyme immunoassay as described previously (Katoh-Semba et al., 2000).

Immunofluorescence microscopy. Cortical neurons were fixed in $2 \%$ paraformaldehyde (PFA) for $20 \mathrm{~min}$ at room temperature or at $-20^{\circ} \mathrm{C}$ with methanol for $10 \mathrm{~min}$, followed by permeabilization $0.1 \%$ Triton X-100 in PBS. Immunostaining was performed using anti-PSD-95, antisynapsin I, and anti-NRP-1 antibodies. To visualize spine-like protrusion, some neurons were stained with rhodamine-phalloidin. Four-well dishes were then mounted in glycerol mountant and analyzed using Olympus Optical (Tokyo, Japan) IX-71 microscopy using a $40 \times$ objective. In some cases, fluorescence microscopic images were gained by using a laser scanning microscope (LSM510) with a water-immersed objective at $63 \times$ (C-Apochromat) equipped with Axioplan 2 imaging microscope (Zeiss, Oberkochen, Germany).

Quantitative analysis of maturation of spines after application of Sema3A. In the cultured neurons stained with anti-PSD-95 and NRP-1 antibodies, the area of PSD-95- or NRP-1-positive cluster was quantified using LSM-5 Image software (Zeiss). In our present study, we counted PSD-95, synapsin I, or double-positive clusters with an area $>0.1 \mu \mathrm{m}^{2}$. Dendritic protrusions were defined as spines that have an enlargement at the tip. Thin protrusions without enlargement were defined as filopodialike protrusions (Boda et al., 2004). For each dendrite, dendritic spine and filopodia densities and the length of dendrites were quantified. Percentage of spines was calculated from the ratio of spines to spines plus filopodia.

Silver-impregnated sections of wild-type, fyn, and sema3A mutant mice were imaged using Zeiss Axioplan2 microscope. Drawing was performed using Olympus Optical BX40 microscopy equipped with a camera lucida. Only pyramidal neurons in layer $V$ that satisfied the following criteria were included: (1) complete impregnation (including all dendrites), not obscured by other neurons or artifacts; (2) clear image; and (3) visibility of at least three basal dendrites. For each neuron, dendritic spine density and the length of dendrites were quantified. A minimum of 20 spiny neurons with pyramidal morphology were selected from $\sim 10$ Golgi-stained sections (two neurons per each section) for quantification. In both images obtained with primary culture and Golgi impregnation, unbranched dendritic protrusions with a head showing a bouton-like structure were defined as dendritic spines. Headless protrusions and filopodia-like microspikes were distinguished from the defined spine. The number of spines per $100 \mu \mathrm{m}$ of apical or basal dendrite shaft was calculated from a neuron (Murai et al., 2003).

In situ hybridization using digoxigenin-labeled $c R N A$ probes. The in situ hybridization for Sema3A or NRP-1 was performed by digoxigeninlabeled riboprobes (Kagoshima et al., 2001). C57BL/6 mice (Charles River Japan, Tokyo, Japan) were deeply anesthetized with diethyl ether and perfused intracardially with $4 \%$ paraformaldehyde in PBS. The brains were removed and postfixed in $4 \%$ paraformaldehyde overnight. After cryoprotected with $30 \%$ sucrose, the brains were embedded by Tissue-Tek O.C.T Compound (Sakura Finetechnical, Tokyo, Japan), and sagittal cryostat sections (16 $\mu \mathrm{m}$ thick) were collected on Superfrost slides (Matsunami Glass, Osaka, Japan) and stored at $-80^{\circ} \mathrm{C}$ before use. The brain sections were briefly digested with $1 \mu \mathrm{g} / \mathrm{ml}$ proteinase $\mathrm{K}$ (Invitrogen) in PBS and refixed with 4\% PFA for $30 \mathrm{~min}$, and the sections were then hybridized with antisense and sense probes at $65^{\circ} \mathrm{C}$ overnight. The final concentration of the probes diluted in the hybridization solution (containing 50\% formamide, 5\% SSC, pH 4.5, 1\% SDS, $50 \mu \mathrm{g} / \mathrm{ml}$ yeast tRNA, and $50 \mu \mathrm{g} / \mathrm{ml}$ heparin) was $4 \mu \mathrm{g} / \mathrm{ml}$ (1:1 mixture of two different probes). The slides were washed at $65^{\circ} \mathrm{C}$ in $50 \%$ formamide, $5 \times$ SSC, and $1 \%$ SDS and then at $65^{\circ} \mathrm{C}$ in $50 \%$ formamide and $2 \times$ SSC twice. The slides were incubated for $1 \mathrm{~h}$ at room temperature with 10\% BSA and then overnight at $4^{\circ} \mathrm{C}$ with alkaline phosphatase-conjugated antidigoxigenin antibodies (Roche Molecular Biochemicals, Meylan, France). Bound digoxigenin-labeled probes were detected using 5-bromo-4-chlorindolyl-phosphate and nitroblue-tetrazolium-chloride (Roche Molecular Biochemicals, Meylan, France). No signal was detected using the sense probes.

Immunoblot analysis. Brain samples were homogenized in immunoprecipitation buffer (200 mM Tris- $\mathrm{HCl}, \mathrm{pH} 7.4,150 \mathrm{~mm} \mathrm{NaCl}, 1 \mathrm{~mm}$ EDTA, $1 \mathrm{~mm} \mathrm{Na}_{3} \mathrm{VO}_{4}, 1 \%$ Nonidet P-40, $50 \mu \mathrm{M} \gamma$-amidinophenylmethanesulfonyl fluoride, and $10 \mu \mathrm{g} / \mathrm{ml}$ aprotinin). The samples were then centrifuged $15,000 \mathrm{rpm}$ for $20 \mathrm{~min}$ at $4^{\circ} \mathrm{C}$, and supernatants were used for immunoblot analysis of NRP-1 and Sema3A detection using 
anti-NRP-1 and rabbit anti-Sema3A (epitope corresponding to amino acids 103-402, mapping to the conserved extracellular semaphorin domain of Sema3A of human origin; Santa Cruz Biotechnology, Santa Cruz, CA). In general, Sema3A and NRP-1 were detectable in NP-40soluble lysates of postnatal day 0 (P0) to 4 -week-old brains. However, Sema3A was hardly detected in P0 brain lysate. For detection of Sema3A in brain at $\mathrm{P} 0$, the pellets obtained were dissolved in $4 \times$ sample buffer (125 mm Tris-HCl, pH 6.8, 4\% SDS, and 25\% glycerol) and further sonicated four times for $10 \mathrm{~s}$ each. The solubilized protein solutions after sonication were used for immunoblot analysis.

Golgi staining. The staining of the mouse brain sections with the GolgiCox method was performed as described previously (Sasaki et al., 2002). In brief, brains from mice 3 months and older were dissected out from the skull, and the fresh tissues were placed in a solution consisting of $7 \mathrm{ml}$ of $5 \%$ potassium dichromate, $7 \mathrm{ml}$ of $5 \%$ mercuric chloride, $4 \mathrm{ml}$ of $5 \%$ potassium chromate, and $10 \mathrm{ml}$ of distilled water for 1 month. The tissues were then dehydrated, embedded in $10 \%$ celloidin, cut at $100 \mu \mathrm{m}$ on a sliding microtome, and soaked in $12.5 \% \mathrm{NH}_{4} \mathrm{OH}$ solution.

Statistical significance. Data are shown as mean \pm SEM. The statistical significance of the results was analyzed using one-way ANOVA.

\section{Results}

Sema3A promotes neurite formation and dendritic branching in the cultured neurons

Sema3A is a potent inhibitor of axonal growth and branching of a specific subset of neurons. We found that Sema3A concentration dependently promoted neurite formation and dendrite branching in the cultured E16.5 cortical neurons on 1 or $7 \mathrm{~d}$ in vitro (DIV), respectively (Figs. 1, 2). Sema3A concentration dependently increased the percentage of cells with neurites (Fig. $1 B$ ). Sema3A also increased the number of branching points per neuron in a concentration-dependent manner (Fig. 2A,B). Under this experimental condition, the mean neurite length per cells was not modified by Sema3A (data not shown). In our culture of cortical neurons, cells were classified as pyramidal or nonpyramidal on the basis of morphological features. However, there was no difference in the effects of Sema3A between pyramidal and nonpyramidal neurons. To confirm the effect of Sema3A, we used construct of soluble NRP-1 (sNRP-1) including the extracellular domain but lacking the cytoplasmic domains (Goshima et al., 1999; Kagoshima et al., 2001). When sNRP-1 was added at the same time as Sema3A in the culture, the sNRP-1 blocked the promoting effect of Sema3A on branching formation (data not shown). In our previous study, we showed that lavendustin A, a nonselective tyrosine kinase inhibitor, suppresses Sema3Ainduced growth cone collapse and axonal transport (Sasaki et al., 2002; Li et al., 2004). We tested whether this compound inhibited the effect of Sema3A to promote branching of the cultured neurons. Lavendustin A at the concentration of $3 \mu \mathrm{M}$, which alone did not affect morphology of the cultured neurons, almost completely suppressed Sema3A-induced increase in the total number of branching points per neuron (Fig. 2C). To elucidate the role of Src-type tyrosine kinase(s), we used PP2, a specific Src-type tyrosine kinase inhibitor (Takasu et al., 2002; Karni et al., 2003). In wild-type neurons, PP2, at the concentration of $0.4 \mu \mathrm{M}$, which alone did not affect morphology of the culture neurons, suppressed Sema3A-induced increase in the total number of branching points per neuron. This effect was not mimicked by PP3, the inactive-related compound, suggesting that Src-type tyrosine kinases including Fyn was involved in Sema3A-induced dendritic branching (Fig. 2C). We next examined the effect of Sema3A in cultured neurons from $f y n^{-1-}$ mouse neocortex (Fig. 2D). Strikingly, there were few dendrites, and the branching points were lower than that of wild-type culture (Fig. 2D). Sema3A produced essentially no effects on dendritic branching in $f \mathrm{yn}^{-1-}$ neurons.

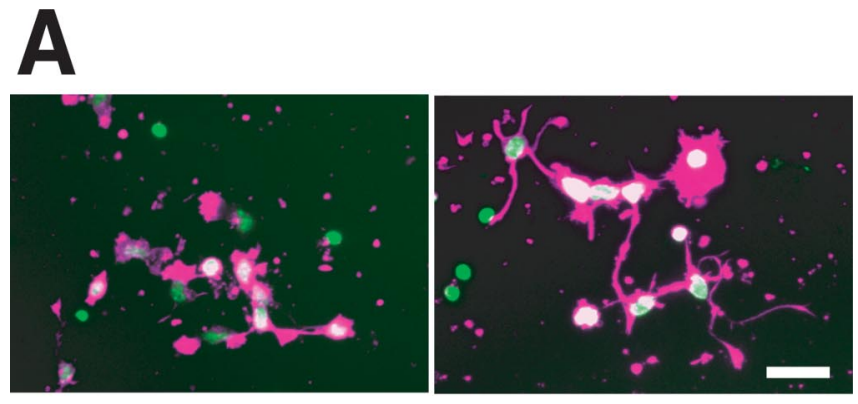

\section{B}

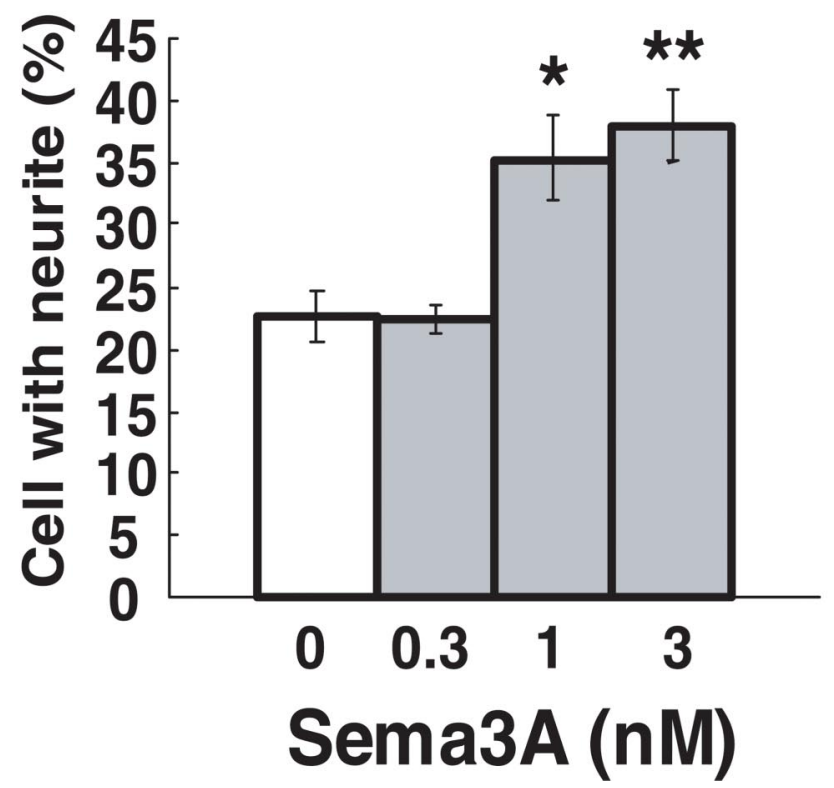

Figure 1. Sema3A induces neurite formation in cortical neurons. $A$, Cultured E16.5 mouse cortical neurons on 1 DIV were applied with Sema3A (left, $0 \mathrm{~nm}$; right, $1 \mathrm{~nm}$ ) and further incubated for $24 \mathrm{~h}$. Neurons were double stained with rhodamine-labeled phalloidin (purple) and DAPI (green). Scale bar, $50 \mu \mathrm{m}$. B, Neurite formation was quantified by scoring the number of cells possessing neurites and expressing them as a percentage of the totals. Neurites were defined as process extensions greater than one cell body in length. Each value represents mean \pm SEM of 20 neurons from four independent cultures. ${ }^{*} p<0.005,{ }^{* *} p<0.001$ compared with vehicle control. The statistical significance of the results was analyzed using one-way ANOVA.

These results together suggest that Sema3A induced branching formation through cascade mediated by Fyn in the cultured cortical neurons.

Sema3A promotes spine maturation and colocalization of PSD-95- and NRP-1- immunoreactive clusters in cultured cortical neurons

Most spines are thought to serve as recipients of synaptic inputs (Yuste and Bonhoeffer, 2004). To examine the effects of Sema3A on synapse maturation, we therefore visualized spines using phalloidin staining in cortical neurons derived from E16.5 brains on 14 DIV. Neurons treated with Sema3A showed a higher density of spine-like protrusion with bulbous heads (Fig. $3 A$ ). This effect of Sema3A appeared to be seen with pyramidal and nonpyramidal neurons (data not shown). In the cortical neurons, most of the PSD-95-immunoreactive clusters were localized with spine (Figs. 3, 4) (see Fig. 6). The sizes of PSD-95 clusters were within the 
range of $0.1-0.6 \mu \mathrm{m}^{2}$, which was comparable with that in another study (Okabe et al., 2001). Sema3A concentration dependently increased the density of the PSD95-immunoreactive clusters per dendrite (Fig. $3 A, B$ ). Sema3A also increased the cluster size of PSD-95 (Fig. 3C). To confirm that the clustering of the postsynaptic marker proteins was associated with spine maturation in culture, we compared images of rhodamine-phalloidin staining and PSD-95 clusters. There was an extensive colocalization of PSD-95 clusters with spine-like protrusions after Sema3A treatment (Fig. 3Ad). To confirm a specific effect of Sema3A, we used the construct of sNRP-1. When sNRP-1 was added at the same time as Sema3A in the culture, the sNRP-1 blocked the promoting effect of Sema3A on PSD-95 cluster formation (Fig. 3C).

In addition, we found that Sema3A treatment also increased the percentage of spines or filopodia that contained PSD-95 clusters. The percentages of spines or filopodia containing PSD-95 clusters with and without Sema3A were $39.4 \pm 2.04$ and $26.4 \pm 2.18 \%$, respectively $\left({ }^{\star} p<0.05 ; n=\right.$ 1700-2200 neurites from three independent experiments). This alteration, however, was not accompanied by an increase in the density of dendritic spines or filopodia. The percentages of spine calculated as the ratio of the number of spines to that of spines plus filopodia with and without Sema3A were $90.6 \pm 0.93$ and $89.7 \pm$ $1.06 \%$, respectively. This result suggests that Sema3A promoted spine maturation rather than formation.

It is possible that the effects of Sema3A on dendritic spines are secondary rather than a direct effect on the maturation of dendritic spines. We measured the level of BDNF and NT-3 in the cell extracts and the conditioned medium with and without Sema3A, because these factors have been known to induce dendritic spines in the cultured cortical neurons. BDNF was essentially below detection limit in the cultured E16.5 cortical neurons on 14 DIV. On the other, the contents of NT-3 in the conditioned medium and cell extracts of cultured neurons from E16.5 mouse on 14 DIV were detectable and were $8.9 \pm 0.3$ $(n=3)$ and $22.3 \pm 2.1 \mathrm{pg} /$ well, respectively. There were no significant changes in the levels of NT-3 in the cell extracts and the conditioned medium with and without Sema3A treatment (data not shown).

To localize the site(s) of action of Sema3A in the cortical neurons, we performed double staining with anti-PSD95 and NRP-1 antibodies in the cultured neurons. We found that some of the NRP-1-positive structures were colocalized with PSD-95 clusters and the other in close contact with spine-like protrusions (Fig. 4).
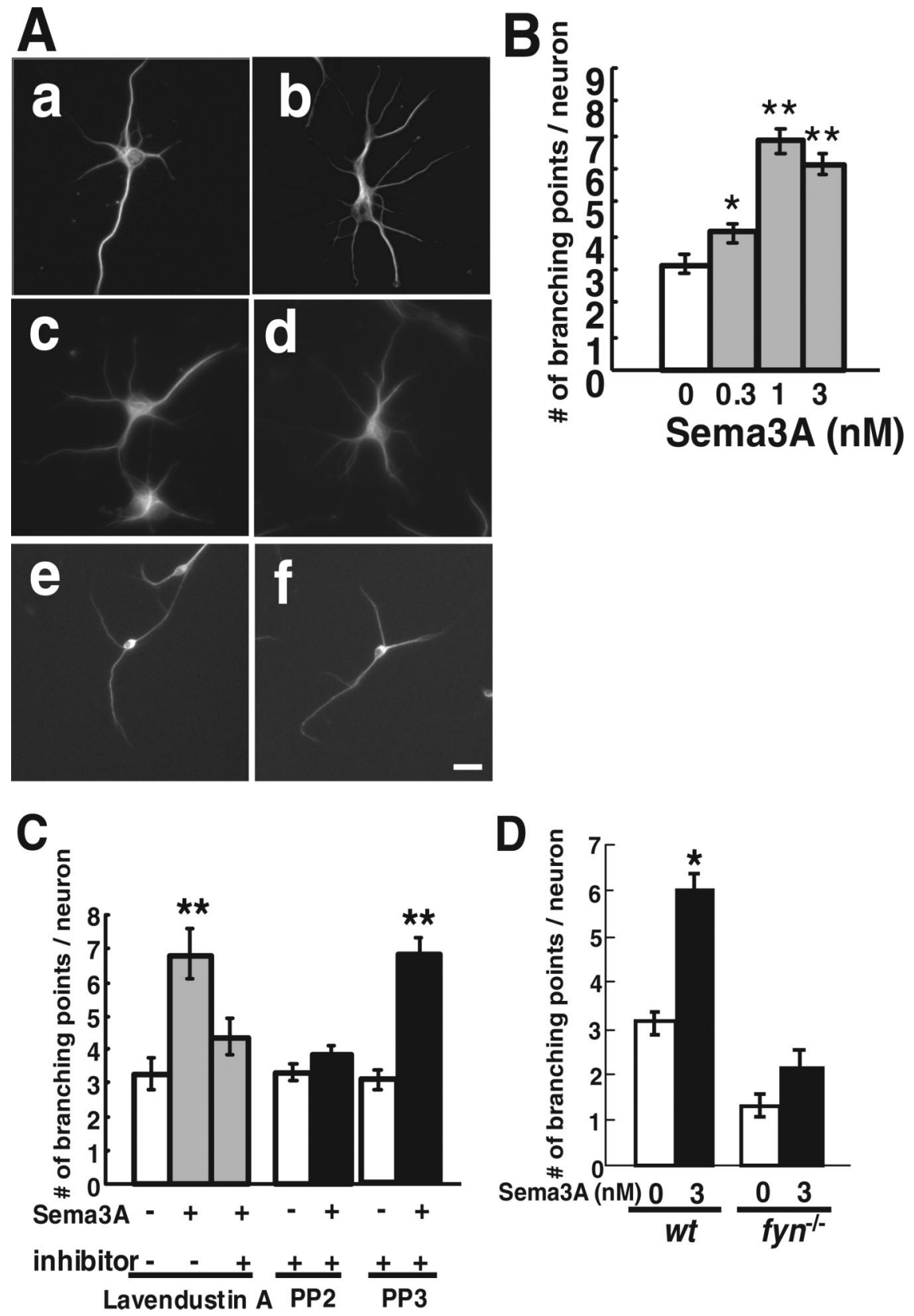

Figure 2. Sema3A induces dendritic branching in cortical neurons. $\boldsymbol{A}$, Morphological changes of the cultured neurons from E16.5 mouse on 7 DIV. The wild-type cortical neurons applied with $(\boldsymbol{b}, \boldsymbol{d})$ and without $(\boldsymbol{a}, \boldsymbol{c})$ Sema3A ( $3 \mathrm{~nm})$ and the fyn-deficient cortical neurons applied with $(\boldsymbol{f})$ and without $(\boldsymbol{e})$ Sema3A ( $3 \mathrm{~nm})$ were immunostained by anti-MAP2 antibody. Lavendustin A ( 3 $\mu \mathrm{m})$, a tyrosine kinase inhibitor $(\boldsymbol{c}, \boldsymbol{d})$, or vehicle control $(\boldsymbol{a}, \boldsymbol{b})$ was applied to the cultured neurons 30 min before application of Sema3A. Scale bar, $20 \mu \mathrm{m}$. B, Quantitative analysis of Sema3A-induced branching. Total numbers of branch points were estimated for 20 neurons from four independent cultures. C, Quantitative analysis of suppressive effect of lavendustin A (3 $\mu \mathrm{M})$, PP2 $(0.4 \mu \mathrm{m})$, or PP3 $(0.4 \mu \mathrm{m})$ on the Sema3A-induced branching. ${ }^{* *} p<0.01$ compared with corresponding control. D, Quantitative analysis of Sema3A-induced branching in fyn-deficient mouse neurons. wt, Wild type. ${ }^{*} p<0.05,{ }^{* *} p<0.001$ compared with vehicle control or Sema3A ( $3 \mathrm{~nm}$ ) alone. Statistical significance was assessed with a one-way ANOVA.

When the cultured cortical neurons were exposed to Sema3A, the cluster size of PSD-95 was markedly enhanced (Fig. 4b,d). The areas of NRP-1 clusters with and without Sema3A were $0.67 \pm 0.037$ and $0.23 \pm 0.008 \mu \mathrm{m}^{2}$, respectively $\left({ }^{\star} p<0.001\right.$; $n=20-25$ neurites from four independent cultures). An extensive colocalization of PSD-95 and NRP-1 or actin-rich protrusion was seen. The percentages of double-positive spots with and without Sema3A were $66.9 \pm 9.3$ and $53.9 \pm 5.6 \%$, respectively (Fig. $4 d$ ). 

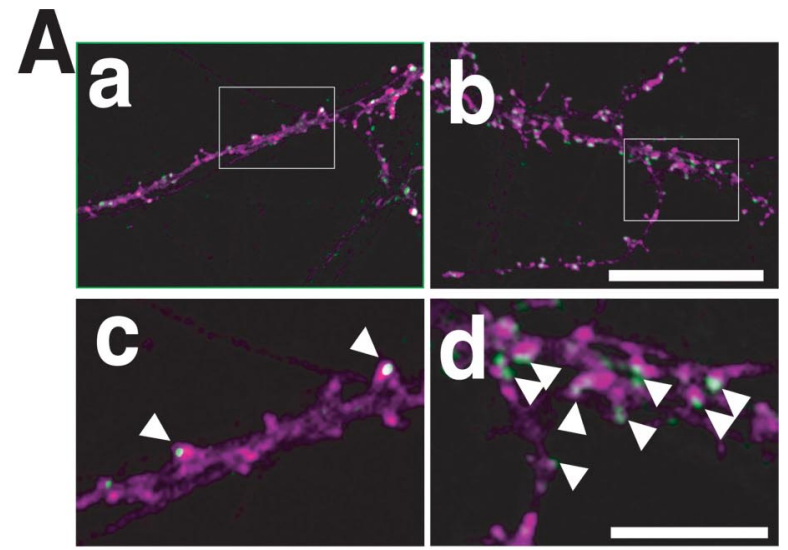

B
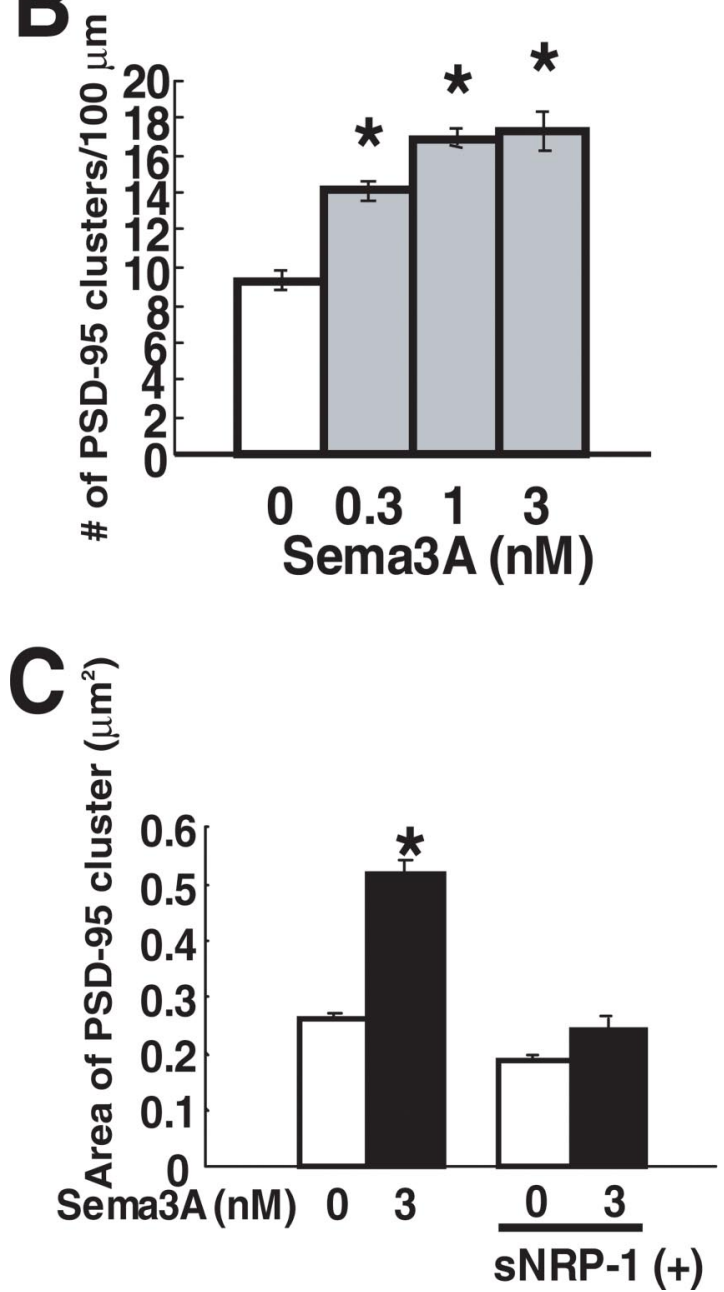

Figure 3. Sema3A increases PSD-95 immunoreactive clusters in cultured cortical neurons. $\boldsymbol{A}$, The cultured E16.5 cortical neurons on 14 DIV were applied with $(\boldsymbol{b}, \boldsymbol{d})$ or without $(\boldsymbol{a}, \boldsymbol{c})$ Sema3A ( 3 nм) and were double stained with anti-PSD-95 (green) and rhodamine-phalloidin (purple). Magnified images of boxed area in $\boldsymbol{a}$ and $\boldsymbol{b}$ are shown in $\boldsymbol{c}$ and $\boldsymbol{d}$, respectively. White color indicates localization of PSD-95 clusters on actin-rich protrusions stained with rhodaminephalloidin on dendrites (arrowheads). Scale bars: $\boldsymbol{b}, 10 \mu \mathrm{m} ; \boldsymbol{d}, 5 \mu \mathrm{m}$. $\boldsymbol{B}$, Sema3A concentration dependently promoted the density of PSD-95-immunoreactive clusters per $100 \mu \mathrm{m}$ of dendritic shaft, estimated from 20 neurons from four independent cultures. ${ }^{*} p<0.001$ compared with vehicle control. C, Quantitative analysis of area size of PSD-95 clusters in culture treated with or without Sema3A. sNRP-1 (30 nm) suppressed the promoting effect of Sema3A on PSD-95 clusters ( $n=78-87$ from two independent cultures). ${ }^{*} p<0.001$ compared with vehicle control. The immunofluorescence was detected by confocal microscopy, and the areas were quantified by LSM-5 image software (Zeiss).
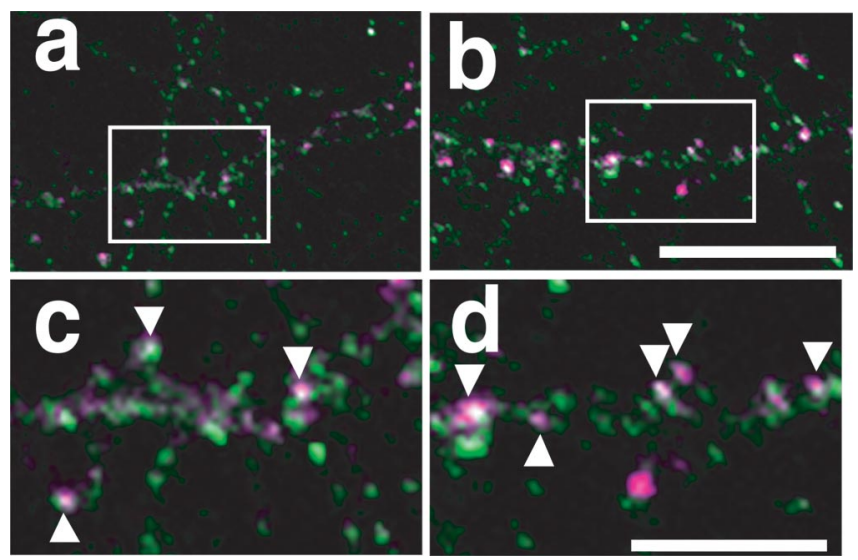

Figure 4. Colocalization of clusters of PSD-95 and NRP-1 on spine-like protrusions on dendrites. The cultured cortical neurons were applied with $(\boldsymbol{b}, \boldsymbol{d})$ or without $(\boldsymbol{a}, \boldsymbol{c}) \operatorname{Sema} 3 \mathrm{~A}(3 \mathrm{~nm})$ and were double stained with anti-PSD-95 (purple) and NRP-1 (green) antibodies. Magnified images of boxed area in $\boldsymbol{a}$ and $\boldsymbol{b}$ are shown in $\boldsymbol{c}$ and $\boldsymbol{d}$, respectively. The white color indicates colocalization of PSD-95 and NRP-1 clusters (arrowheads). Scale bars: $\boldsymbol{a}, \boldsymbol{b}, 10 \mu \mathrm{m} ; \boldsymbol{c}, \boldsymbol{d}, 5 \mu \mathrm{m}$.

PP2, an Src-type tyrosine kinase inhibitor, blocks Sema3Ainduced spine maturation, and Sema3A fails to induce dendritic spines in $\mathrm{fyn}^{-/-}$cortical neurons

In wild-type neurons, the effect of Sema3A on spine morphology was blocked by PP2 but not by PP3 (Fig. 5A-C). Sema3A-induced increases in the density and the area of PSD-95 clusters were also blocked by lavendustin A (Fig. 5D). To further explore possible involvement of Fyn tyrosine kinase, we examined the effect of Sema3A in cultured neurons from $f \mathrm{yn}^{-/-}$mouse neocortex by double staining with anti-PSD-95 antibody and rhodamine-phalloidin (Fig. 5E). Strikingly, the density of spine-like protrusion was quite low when compared with wild-type culture, and there were few PSD-95 clusters on dendrites (Fig. 5 E, F). Sema3A induced neither PSD-95 clustering nor formation of spine-like protrusions on dendrites of cortical neurons from $f \mathrm{yn}^{-/-}$mouse (Fig. $5 E, F$ ). These results together suggest that Sema3A induced maturation of spine and/or spine-like protrusion through a cascade mediated by Fyn in the cultured cortical neurons.

\section{Sema3A increases PSD-95- and synapsin I-immunoreactive} clusters in cultured cortical neurons

It is known that local and stepwise assembly of presynaptic as well as postsynaptic components occurs during the formation of mature spines (Ahmari et al., 2000; Friedman et al., 2000; Okabe et al., 2001). We therefore performed immunostaining of the cultured cortical neurons with synapsin I, a presynaptic marker (Togashi et al., 2002), as well as PSD-95, before and after Sema3A stimulation. In addition to PSD-95 and NRP-1, Sema3A increased the density of synapsin I-immunoreactive clusters. The numbers of synapsin I-positive clusters per $100 \mu \mathrm{m}$ with and without Sema3A were $19.4 \pm 1.40$ and $13.5 \pm 1.14$, respectively. $\left({ }^{*} p<0.05 ; n=20-25\right.$ neurites from four independent experiments) (Fig. 6A). We further determined whether assembly of these presynaptic and postsynaptic markers were closely associated with each other by double staining with anti-PSD-95 and synapsin I antibodies. Sema3A increased the number of PSD-95 clusters (Fig. 6B) and actin-rich protrusions (Fig. 6C) that were apposed to synapsin I-immunoreactive clusters. The numbers of double-positive clusters per $100 \mu \mathrm{m}$ with and without Sema3A were $29.5 \pm 0.12$ and $14.9 \pm 2.09$, respectively $\left({ }^{*} p<0.001 ; n=\right.$ 20-25). 
Expression of sema3A and $n r p-1$ gene in the developing cortex

To determine the expression patterns of the $n r p-1$ gene in the developing mouse cortex, we performed in situ hybridization at several developmental ages. At P0, P10, P15, and 4 week cortex, NRP-1 and Sema3A mRNAs were expressed in complementary patterns in the cerebral cortex (Fig. 7A). At P0, the messages of Sema3A and NRP-1 were diffusely distributed in layers II and III and the deep layers IV and $\mathrm{V}$, respectively (Fig. 7A). At P10 to 4 weeks, the Sema3A and NRP-1 messages were confined to layer II and layer V, respectively. In 4-week-old cortex, the expression levels of these two molecules were markedly downregulated but sustained (Fig. 7A). Sema3A and its receptors were therefore highly expressed during the synaptogenic period of P8-P18 (Jontes and Smith, 2000). These expression patterns support the idea that the Sema3ANRP-1 interaction is involved in the development of dendrites and spines in the cerebral cortex in vivo. Using immunoblot analysis of brain lysates, we confirmed that the protein levels of NRP-1 were approximately correlated with its expression levels through P0 to 4 weeks revealed by in situ hybridization (Fig. 7B). Sema3A was also detected through P0 to 4 weeks in brain lysates, being correlated with its expression levels (Fig. 7B). For detection of Sema3A in the brain lysates from P0 mice, the pellets was sonicated before SDS-PAGE.

Lowered dendritic spine density in fynand sema3A-deficient mice

We reported previously that the sema3A gene shows strong genetic interaction with fyn for apical dendrite guidance in the cerebral cortex (Sasaki et al., 2002). In the present study, we further studied phenotypes of neurons in $f y n^{-/-}, \operatorname{sema} 3 A^{-/-}$, and sema3 $A^{+/-} ; \mathrm{fyn}^{+/-}$mice using Golgiimpregnation analysis. We found that spine density was decreased in the layer $\mathrm{V}$ pyramidal neurons in $\mathrm{fyn}^{-/-}$and sema3 $A^{-1-}$ mice (Fig. 8A,B). Furthermore, sema $3 A$ gene showed strong genetic interaction with $f y n$ for the number of spine per dendrite in the cerebral neurons (Fig. $8 \mathrm{~B}$ ). Neurons in the cerebral cortex of the double-heterozygous mice showed the decreased spine density phenotype, whereas the neurons of single heterozygous mice (sema3 $A^{+/-}$or $f y n^{+/-}$) showed similar levels of spine density as the wild type. These results demonstrate that sema3A gene shows strong genetic interaction with $f y n$ for spine formation in the
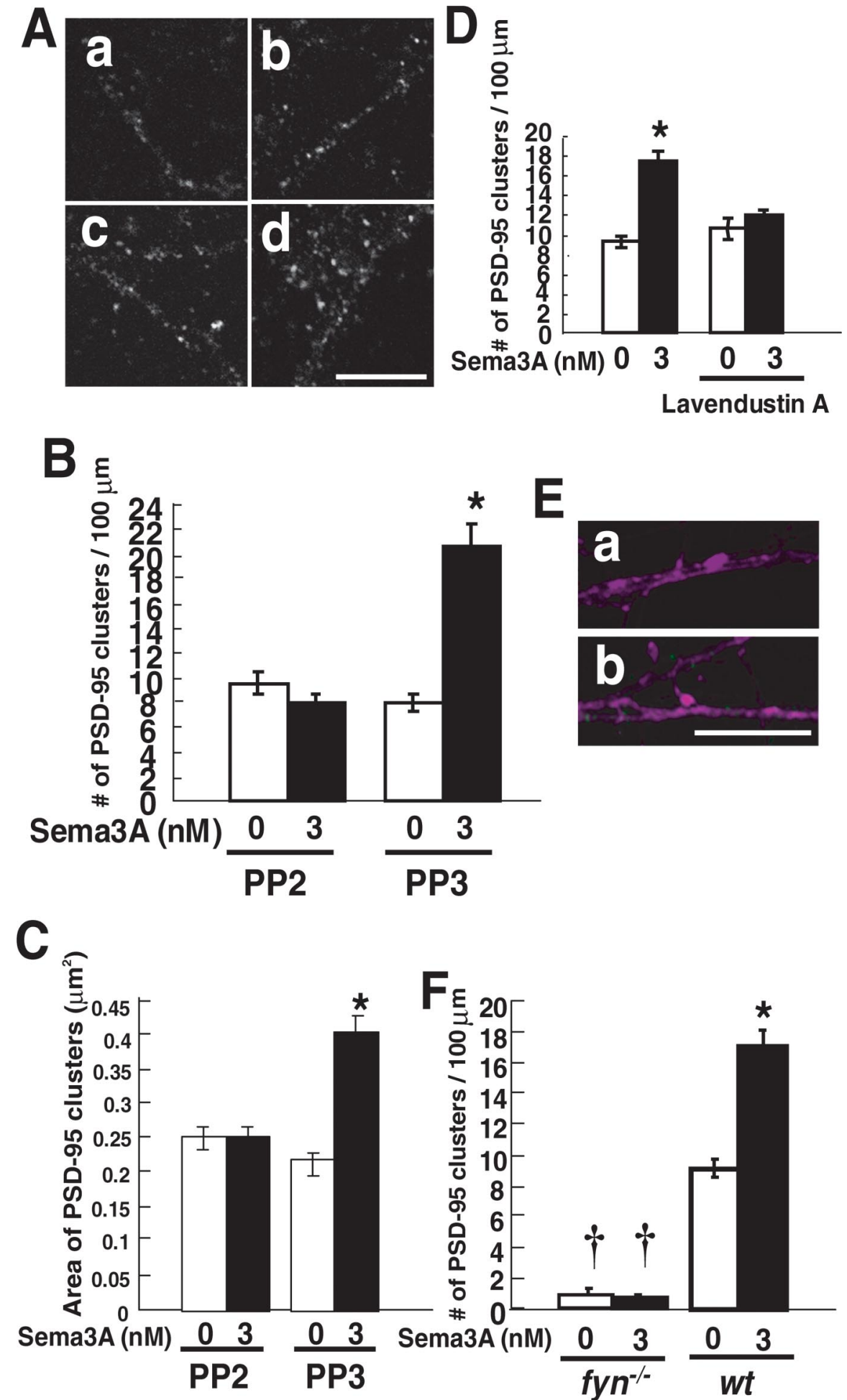

Figure 5. Src-type tyrosine kinase inhibitors block Sema3A-induced PSD-95 clustering. PP2 but not PP3 suppressed the effect of Sema3A (3 nm) on PSD-95 clusters, and Sema3A fails to induce PSD-95 cluster formation in fyn ${ }^{-1-}$ neurons. $A$, PSD-95 clusters in cultured cortical neurons treated with $(\boldsymbol{b}, \boldsymbol{d})$ and without $(\boldsymbol{a}, \boldsymbol{c}) \operatorname{Sema3A}$. PP2 $(\boldsymbol{a}, \boldsymbol{b})$ or PP3 $(\boldsymbol{c}, \boldsymbol{d})(0.4 \mu \mathrm{m})$ was applied 30 min before Sema3A. Scale bar, $10 \mu \mathrm{m} . \boldsymbol{B}$, Quantitative analysis of the effects of PP2 and PP3 on the density of PSD-95 clusters. Images of 10 typical neurons from two independent culture preparations were recorded, and the density of PSD-95-clusters was measured. C, Quantitative analysis of the effects of PP2 and PP3 on the area of PSD-95 clusters. Images of 10 typical neurons from two independent culture preparations were recorded, and the area of PSD-95 clusters was measured. D, Quantitative analysis of the effect of lavendustin A on the density of PSD-95 clusters. $\boldsymbol{E}$, The cultured cortical neurons from fyn ${ }^{-/-}$mice were applied with (b) or without (a) Sema3A (3 nм) and were double stained with anti-PSD-95 (green) and rhodamine-phalloidin (purple). Scale bar,

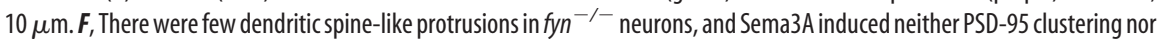
spine-like protrusion on dendrites. ${ }^{*} p<0.001$ compared with Sema3A at $0 \mathrm{~nm} ;{ }^{\dagger} p<0.001$ compared with corresponding value in wild type (wt). 


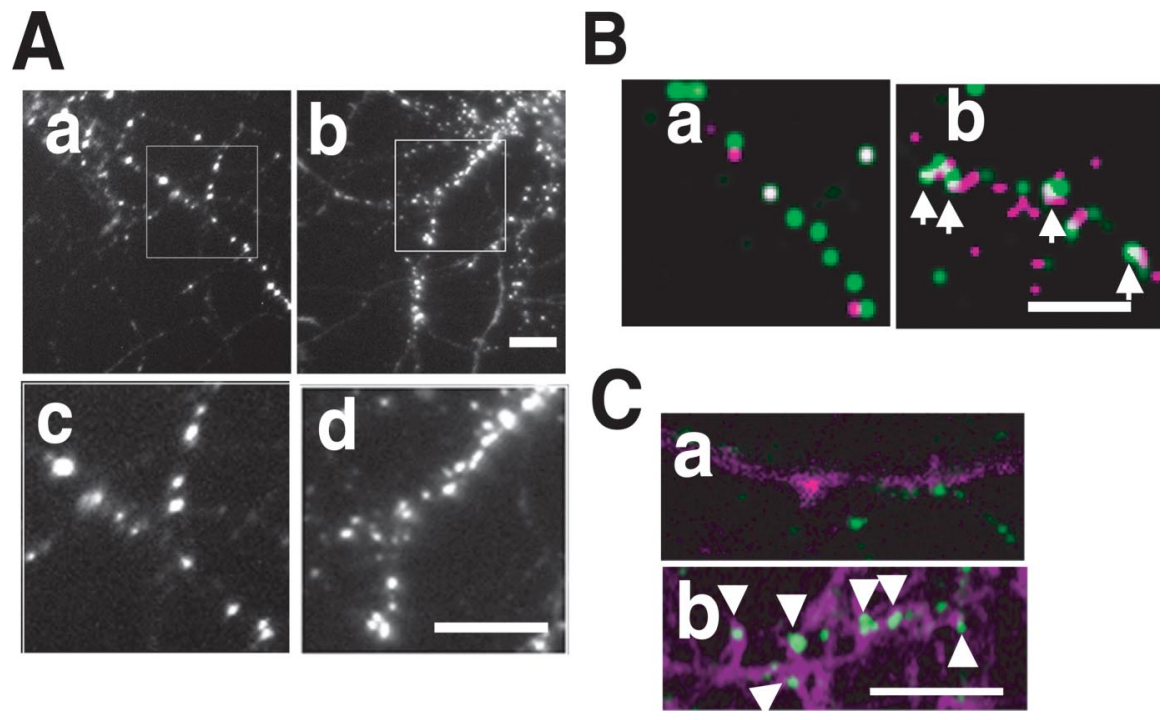

Figure 6. Sema3A induces cluster formation of PSD-95 and synapsin I on actin-rich protrusions. $A$, Sema3A increased synapsin I-immunoreactive clusters in cortical neurons. Cultured E16.5 mouse cortical neurons on 14 DIV were treated with $(\boldsymbol{b}, \boldsymbol{d})$ or without $(\boldsymbol{a}, \boldsymbol{c})$ Sema3A ( $3 \mathrm{~nm})$ for $24 \mathrm{~h}$. Cortical neurons were stained with anti-synapsin I antibody. Magnified images of boxed area in $\boldsymbol{a}$ and $\boldsymbol{b}$ are shown in c and $\boldsymbol{d}$, respectively. Scale bars, $10 \mu \mathrm{m}$. $\boldsymbol{B}$, Sema3A increased the density of synapsin I clusters (green) in apposition of the PSD-95 clusters (purple) in the cortical neurons. The cultured cortical neurons were treated with (b) or without (a) Sema3A (3 nм) for $24 \mathrm{~h}$. The neurons were double stained with anti-synapsin I and anti-PSD95 antibodies. Superimposition of images, illustrating clusters of PSD-95-immunoreactive spots, were closely associated with those of synapsin I (arrows). Scale bar, $10 \mu \mathrm{m}$. C, Superposition of immunopositive clusters of synapsin I (green) and rhodamine-phalloidin (purple) in cultured neurons with (b) or without (a) Sema3A. Arrowheads indicate synapsin I clusters contacted with rhodamine-phalloidin fluorescent signals. Scale bar, $10 \mu \mathrm{m}$

cerebral cortex as for apical dendrite guidance. Conversely, the spine density of layer III pyramidal neurons in sema3 $A^{-/-}$mice was not different from that in wild-type animals (data not shown).

\section{Discussion}

Dendritic spines are the principal postsynaptic targets for excitatory synapses. Dendritic spines, which consist mainly of actin filament, undergo morphological changes in a developmentally regulated and activity-dependent manner (Okabe et al., 2001; Li et al., 2002; Vaillant et al., 2002; Wong and Ghosh, 2002; Hua and Smith, 2004; Yuste and Bonhoeffer, 2004). The molecular mechanisms that govern spine morphogenesis have attracted significant interest because changes in their morphology are implicated in synaptic plasticity and neuronal connection (Luo et al., 1996; Horch et al., 1999; Nakayama et al., 2000; Tashiro et al., 2000; Ishikawa et al., 2003; Oinuma et al., 2004). We here provide for the first time the evidence that Sema3A, a repulsive axon guidance molecule, through Fyn tyrosine kinase, plays a critical role in regulating the spine maturation of the cortical neurons. This is an unexpected finding because the same ligand Sema3A could induce growth cone collapse (Raper, 2000; Pasterkamp and Kolodkin, 2003; Fujisawa, 2004) and spine maturation in dendrites: these morphological changes are considered to be associated with depolymerization and polymerization of actin cytoskeleton, respectively (Aizawa et al., 2001; Yuste and Bonhoeffer, 2004). Sema3A increased the PSD-95 cluster-containing spines and filopodia without changing their densities. It therefore could be possible that the effects of Sema3A signaling on dendritic spine morphogenesis are the result of assembly of synaptic components including PSD-95 on dendritic spine or filopodia. Because PSD-95 proteins are a core part of the structure of the postsynaptic site and anchor glutamate receptors in the dendritic spine
(Yuste and Bonhoeffer, 2004), spines containing PSD-95 clusters may be more stable than those without PSD-95 clusters. This may explain our finding of the lowered spine density in sema3A-deficient mice with the Golgi-impregnation method. Sema3A also induced dendritic branching. It may be possible that the effect of Sema3A is part of a general effect, such as regulation of neural activity, on dendritic growth and branching (Okabe et al., 1999).

The mechanisms of these opposite actions are unknown. It has been shown that repulsion to Sema3A is converted to attraction by activation of the cGMP pathway (Song et al., 1998; Nishiyama et al., 2003). In the cerebral cortex, apical dendrites toward the pial surface are regulated by Sema3A, and asymmetric localization of soluble guanylate cyclase in developing apical dendrite is required for the chemoattractant effect of Sema3A (Polleux et al., 2000). Thus, the asymmetric localization of such intracellular second messengers including guanylate cyclase might confer such distinct Sema3A responses. It is also plausible that Sema3A promotes actin polymerization or spine formation through pathway(s) involving activation of Rnd1, a novel Rho-like GTPase (Nobes et al., 1998) that specifically interact with plexin-A1 (Zanata et al., 2002). Indeed, Rnd1 appears to have a bifunctional property on actin reorganization: Rnd-1 induces actin depolymerization in fibroblast (Nobes et al., 1998), but Rnd1 in cultured rat hippocampal neurons has been shown to promote the elongation of dendritic spines (Zanata et al., 2002; Ishikawa et al., 2003).

Recent experiments provide evidence that the axon guidance signaling pathway can directly regulate microtubule dynamics (Gundersen and Cook, 1999; Zhou and Cohan, 2004). In cultured neurons, we observed that Sema3A per se elicited dendritic branching. In this study, the branching effect of Sema3A was blocked by sNRP-1, lavendustin A, and PP2 and was markedly suppressed in $\mathrm{fyn}^{-/-}$neurons. These results suggest that the signaling pathway for the dendrite branching and spine maturation are identical or at least overlapping. We reported recently that Cdk5 primarily phosphorylates CRMP2 at serine 522 and glycogen synthase kinase $3 \beta$ secondarily phosphorylates CRMP2 at threonine 509, and this phosphorylation of CRMP2 plays a critical role in Sema3A signaling. The sequential phosphorylation of CRMP2 reduces the association of CRMP2 with tubulin (Uchida et al., 2005). Sema3A may therefore induce branching through reorganization of microtubule triggered by sequential phosphorylation of CRMP2.

Expression of sema $3 A$ and $n r p-1$ genes in the cerebral cortex at the stage of synaptogenesis suggests that Sema3A plays a role in regulating spine morphology. Immunocytochemical observations indicate that NRP-1 is detected on both axons and dendrites of cortical neurons (Polleux et al., 2000; Sasaki et al., 2002). Our present study demonstrates that some of the NRP-1immunopositive clusters were colocalized with PSD-95 and closely juxtaposed to synapsin I-positive clusters. Furthermore, Sema3A induced colocalization of NRP-1 and PSD-95 clusters on 
dendritic spine-like protrusions, accompanied by an increase in the cluster size of PSD-95 and NRP-1. These results suggest that the assembly of PSD-95 and NRP-1containing postsynaptic structure is highly correlated with the accumulation of both presynaptic and postsynaptic molecules. NRP-1, expressed at the axonal growth cones, is considered to be responsible for axon navigation by Sema3A (Fan and Raper, 1995; Goshima et al., 1999; Li et al., 2004). Our finding is the first observation showing that NRP-1 is also localized at postsynaptic dendritic spine-like protrusion, on which Sema3A can induce NRP-1 clustering. This postsynaptic NRP-1 clustering could provide an effective molecular mechanism for achieving localized actin assembly at the site of Sema3A signaling on dendrites as well as growth cones (Fournier et al., 2000). Sema3A also increased immunoreactive clusters of synapsin I in the cultured cortical neurons. Importantly, local concentration of synapsin I was associated with changes in clustering of PSD-95 in spines across the synaptic junction. This suggests that Sema3A was involved in the assembly of both presynaptic and postsynaptic structures. Given the fact that NRP-1 is present on both axons and dendrites, Sema3A can act on both axons and dendrites to assemble these presynaptic and postsynaptic components. Such morphological changes may be associated with local protein synthesis, because local protein synthesis is required for synapse formation and synaptic plasticity (Kang and Schuman, 1996; Martin, 2004). Indeed, Sema3A can induce local activation of eukaryotic translation initiation factor $4 \mathrm{E}$, a translation initiation factor, in growth cones (Campbell and Holt, 2001; Li et al., 2004) through Sema3A signaling pathway mediated by Fyn and Cdk5 (Sasaki et al., 2002; Li et al., 2004).

We demonstrated that Fyn tyrosine kinase plays a pivotal role in regulating spine morphogenesis. In $\mathrm{fyn}^{-1-}$ neurons, there were essentially no spine-like protrusion, and Sema3A failed to induce morphological changes in dendrites. PP2, an Src-type tyrosine kinase inhibitor, but not PP3, the inactive-related compound (Takasu et al., 2002; Karni et al., 2003), suppressed Sema3A-induced clustering of PSD-95. The Sema3A effect was also blocked by lavendustin A, a nonselective tyrosine kinase inhibitor, which potently blocks Sema3A-induced responses (Sasaki et al., 2002; Li et al., 2004). These results together indicate that Fyn is involved in Sema3A-induced clustering of PSD-95. The relevant substrates of Fyn may include Cdk5 (Sasaki et al., 2002) and other molecules playing roles in synaptic transmission. For example, EphrinB2-induced potentiation of NMDA

B

Sema3A

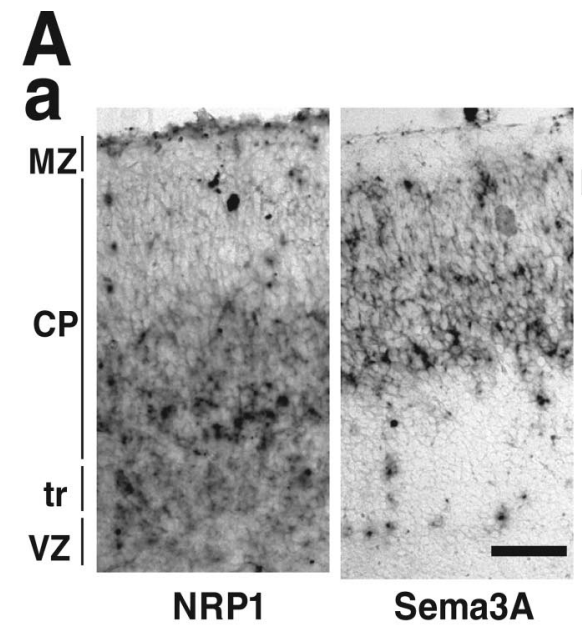

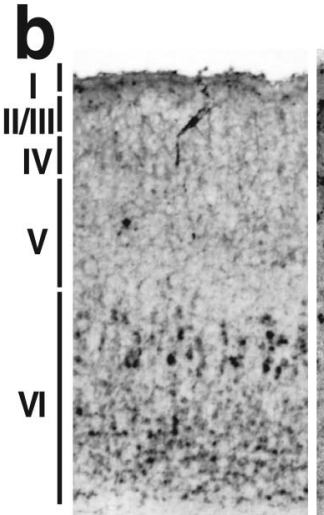

NRP1

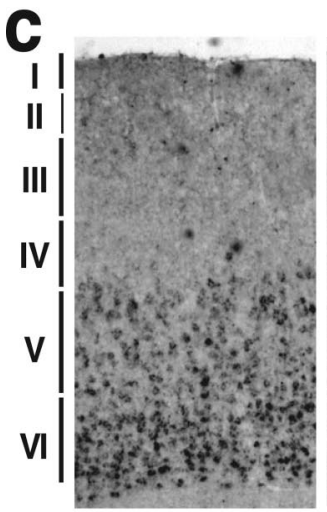

NRP1

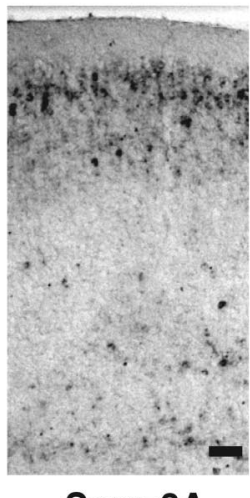

d

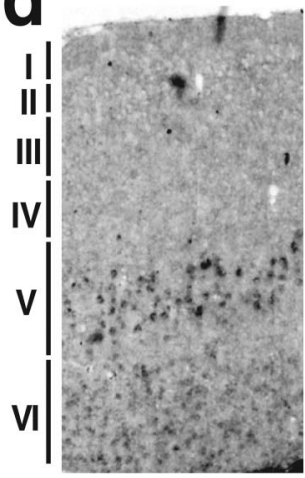

NRP1
Sema3A

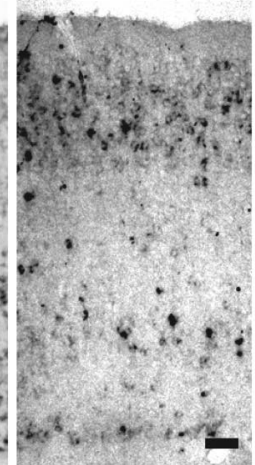

Sema3A

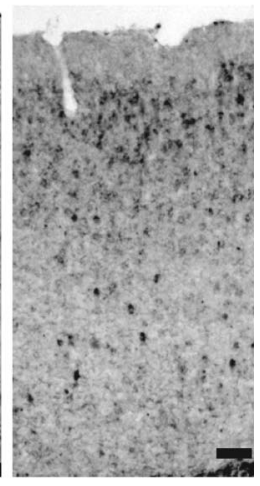

Sema3A
Soluble

Insoluble
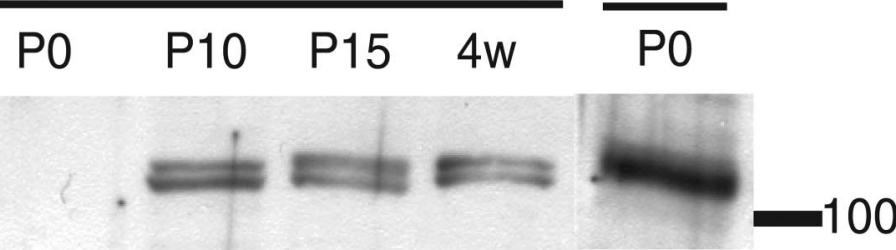

PO

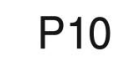

P15

$4 w$

Figure 7. Embryonic and early postnatal expression of $n r p-1$ and sema3A genes in the cortex. A, Mouse P0 (a), P10 (b), P15 (c) and 4-week-old ( $(\boldsymbol{d})$ sagittal sections processed for in situ hybridization with probe for Sema3A and NRP-1. Cortical layers are shown on the left. Scale bar, $100 \mu \mathrm{m}$. MZ, Marginal zone; $C$, cortical plate; tr, nerve fiber tract; VZ, ventricular zone. $B$, Immunoblot analysis of P0, P10, P15, and 4-week-old brain lysates with anti-Sema3A antibody and anti-NRP-1 antibodies. In general, Sema3A and NRP-1 were detectable in NP-40-soluble lysates of P0 to 4-week-old brains. To detect Sema3A in the brain at the developmental stage of $\mathrm{PO}$, the pellets obtained were dissolved in $2 \times$ the sample buffer and further sonicated (Insoluble). receptor-dependent influx of calcium is associated with tyrosine phosphorylation of NMDA receptor through Src family of tyrosine kinases in primary cortical neurons (Takasu et al., 2002). Clearly, to elucidate whether similar events could be elicited by Sema3A stimulation is an important issue to be addressed. Conversely, our finding provides contrast to the observation that Src and Fyn are not required for laminin-induced formation of $\mathrm{ACh}$ receptor but are necessary for stabilization of the laminin- 


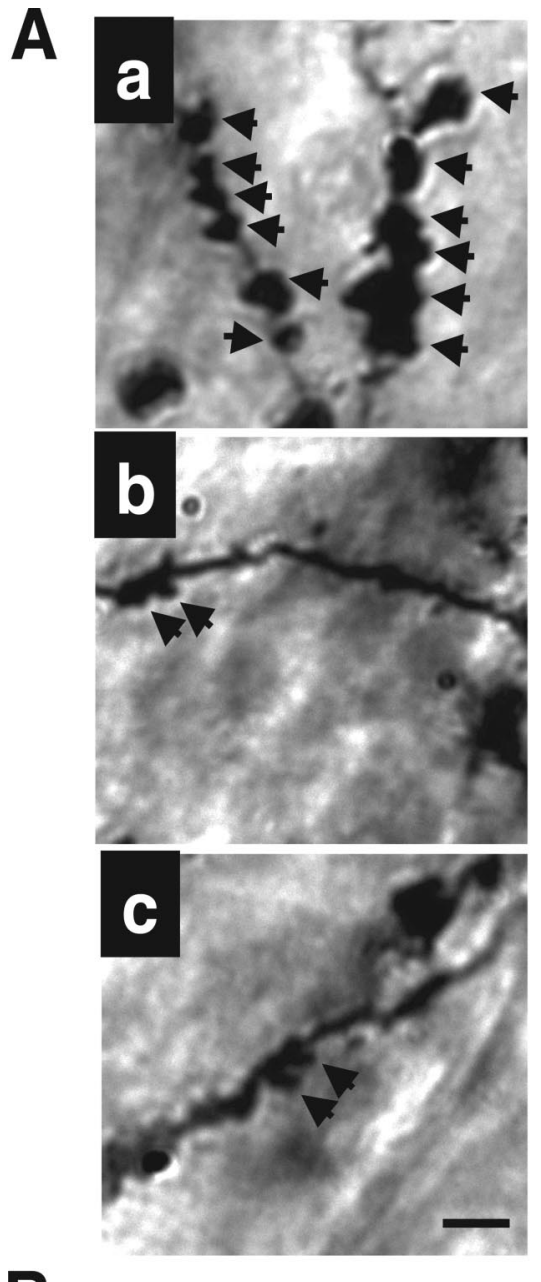

B

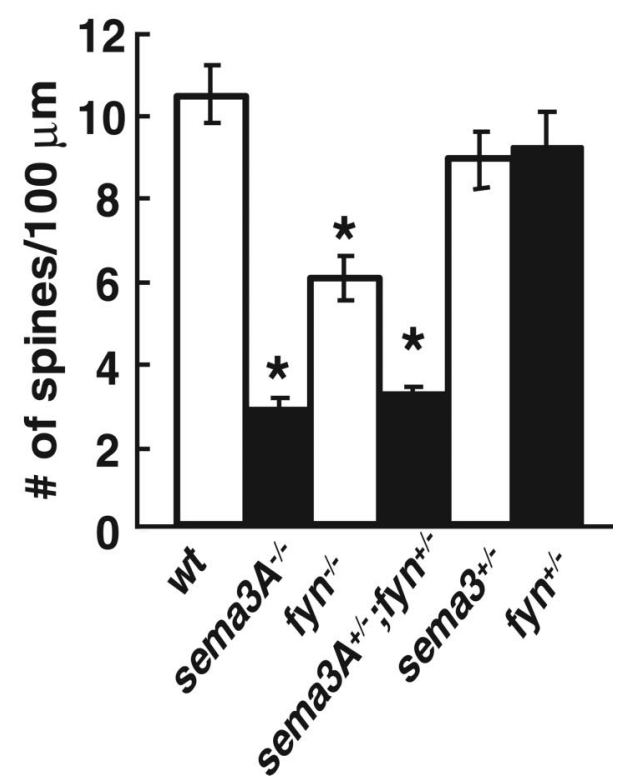

Figure 8. Dendritic spine morphology in cortical neurons in sema $3 A$ and fyn ${ }^{-1-}$ mice. $A_{t}$ Photographs of Golgi impregnation of wild-type $(\boldsymbol{a})$, sema3 $A^{-1-}(\boldsymbol{b})$, and fyn ${ }^{-1-}(\boldsymbol{c})$ mice. Scale bar, $10 \mu \mathrm{m}$. Unbranched dendritic protrusions with a head showing a bouton-like structure were defined as dendritic spines (arrows). $\boldsymbol{B}$, Number of dendritic spines expressed on basal or apical branches of layer $V$ pyramidal neurons. The number of spine per $100 \mu \mathrm{m}$ of dendritic shaft was calculated. Each value represents mean \pm SEM estimated from 20 individual neurons. wt, Wild type. ${ }^{*} p<0.001$ compared with the corresponding value in wild type (wt). induced cluster formation of ACh receptor (Marangi et al., 2002). In $\mathrm{src}^{-/-} ; \mathrm{fyn}^{-/-}$myocytes, laminin-induced ACh receptor clustering is indistinguishable from wild-type cells, but preformed clusters of ACh receptors disperse rapidly after laminin withdrawal (Marangi et al., 2002). We also provide in vivo evidence that the Sema3A-Fyn cascade is involved in spine morphogenesis in the cerebral cortex. The density of dendritic spines is lowered in sema3A- and fyn-deficient adult mice compared with the wildtype. Because the phenotypic defect was not observed in layer III pyramidal neurons, the distribution of neurons showing lowered spine density is confined to the layer $\mathrm{V}$ neurons in sema3A- and fyn-deficient mice, which may be explained by the expression pattern of Sema3A and NRP-1 (Fig. 7). The transheterozygous genetic test using sema3 $A^{+/-} ; f_{y n}{ }^{+/-}$suggests that sema3A and fyn exist on the same genetic pathway. These genetic data speculate that Sema3A regulates spine maturation as well as dendritic patterning (Sasaki et al., 2002) through Fyn tyrosine kinase in vivo. Despite our in vitro findings obtained using cultured neurons (see above), this genetic evidence is important because synaptogenesis is thought to be a protracted phenomenon, taking days or even weeks to complete, whereas spines can arise in minutes (Yuste and Bonhoeffer, 2004).

Although additional studies are required to delineate the signaling cascades by which Sema3A induces dendritic branching and spine maturation, downstream effectors of Sema3A signaling such as Fyn, Cdk5, and LIM kinase have been implicated in spine formation and synaptic plasticity (Aizawa et al., 2001; Meng et al., 2002; Sasaki et al., 2002). More recently, Sema3F, a class 3 semaphorin, has been reported to modulate synaptic transmission in adult hippocampal slices (Sahay et al., 2005). Because Ephrins and Slit 1 have been implicated in dendrite development (Ethell et al., 2001; Henderson et al., 2001; Godenschwege et al., 2002; Whitford et al., 2002; Murai et al., 2003), it appears that axon guidance molecules play roles not only in navigating extending neurites but also in developing dendrites and spines, which in turn have a coordinate effect on neuronal plasticity and connectivity.

\section{References}

Ahmari SE, Buchanan J, Smith SJ (2000) Assembly of presynaptic active zones from cytoplasmic transport packets. Nat Neurosci 3:445-451.

Aizawa H, Wakatsuki S, Ishii A, Moriyama K, Sasaki Y, Ohashi K, Sekine-, Aizawa Y, Sehara-Fujisawa A, Mizuno K, Goshima Y, Yahara I (2001) Phosphorylation of cofilin by LIM-kinase is necessary for semaphorin 3A-induced growth cone collapse. Nat Neurosci 4:367-373.

Boda B, Alberi S, Nikonenko I, Node-Langlois R, Jourdain P, Moosmayer M, Parisi-Jourdain P, Muller D (2004) The mental retardation protein PAK3 contributes to synapse formation and plasticity in hippocampus. J Neurosci 24:10816-10825.

Campbell DS, Holt CE (2001) Chemotropic responses of retinal growth cones mediated by rapid local protein synthesis and degradation. Neuron 32:1013-1026.

Ethell IM, Irie F, Kalo MS, Couchman JR, Pasquale EB, Yamaguchi Y (2001) EphB/syndecan-2 signaling in dendritic spine morphogenesis. Neuron 31:1001-1013.

Fan J, Raper JA (1995) Localized collapsing cues can steer growth cones without inducing their full collapse. Neuron 14:263-274.

Fenstermaker V, Chen Y, Ghosh A, Yuste R (2004) Regulation of dendritic length and branching by Semaphorin 3A. J Neurobiol 58:403-412.

Fournier AE, Nakamura F, Kawamoto S, Goshima Y, Kalb RG, Strittmatter SM (2000) Semaphorin3A enhances endocytosis at sites of receptor-Factin colocalization during growth cone collapse. J Cell Biol 149:411-422.

Friedman HV, Bresler T, Garner CC, Ziv NE (2000) Assembly of new individual excitatory synapses: time course and temporal order of synaptic molecule recruitment. Neuron 27:57-69.

Fujisawa H (2004) Discovery of semaphorin receptors, neuropilin and plexin, and their functions in neural development. J Neurobiol 59:24-33. 
Godenschwege TA, Hu H, Shan-Crofts X, Goodman CS, Murphey RK (2002) Bi-directional signaling by Semaphorin la during central synapse formation in Drosophila. Nat Neurosci 5:1294-1301.

Goshima Y, Kawakami T, Hori H, Sugiyama Y, Takasawa S, Hashimoto Y, Kagoshima-Maezono M, Takenaka T, Misu Y, Strittmatter SM (1997) A novel action of collapsin: collapsin-1 increases antero- and retrograde axonal transport independently of growth cone collapse. J Neurobiol 33:316-328.

Goshima Y, Hori H, Sasaki Y, Yang T, Kagoshima-Maezono M, Li C, Takenaka T, Nakamura F, Takahashi T, Strittmatter SM, Misu Y, Kawakami T (1999) Growth cone neuropilin-1 mediates collapsin-1/Sema III facilitation of antero- and retrograde axoplasmic transport. J Neurobiol 39:579-589.

Goshima Y, Ito T, Sasaki Y, Nakamura F (2002) Semaphorins as signals for cell, repulsion and invasion. J Clin Invest 109:993-998.

Gundersen GG, Cook TA (1999) Microtubules and signal transduction. Curr Opin Cell Biol 11:81-94.

Henderson JT, Georgiou J, Jia Z, Robertson J, Elowe S, Roder JC, Pawson T (2001) The receptor tyrosine kinase EphB2 regulates NMDA-dependent synaptic function. Neuron 32:1041-1056.

Horch HW, Kruttgen A, Portbury SD, Katz LC (1999) Destabilization of cortical dendrites and spines by BDNF. Neuron 23:353-364.

Hua JY, Smith SJ (2004) Neural activity and the dynamics of central nervous system development. Nat Neurosci 7:327-332.

Huber AB, Kolodkin AL, Ginty DD, Cloutier J-F (2003) Signaling at the growth cone: ligand-receptor complexes and the control of axon growth and guidance. Annu Rev Neurosci 26:509-563.

Ishikawa Y, Katoh H, Negishi M (2003) A role of Rnd1 GTPase in dendritic spine formation in hippocampal neurons. J Neurosci 23:11065-11072.

Jontes JD, Smith SJ (2000) Filopodia, spines, and generation of synaptic diversity. Neuron 1:11-14.

Kagoshima M, Ito T, Kitamura H, Goshima Y (2001) Diverse gene expression and function of semaphorins in developing lung: positive and negative regulatory roles of semaphorins in lung branching morphogenesis. Genes Cells 6:559-571.

Kang H, Schuman EM (1996) A requirement for local protein synthesis in neurotrophin-induced hippocampal synaptic plasticity. Science 273:1402-1406.

Karni R, Mizrachi S, Reiss-Sklan E, Gazit A, Livnah O, Livitzki A (2003) The pp60c-Src, inhibitor PP1 is non-competitive against ATP. FEBS Lett 537:47-52.

Katoh-Semba R, Takeuchi IK, Semba R, Kato K (2000) Neurotrophin-3 controls proliferation of granular precursors as well as survival of mature granule neurons in the developing rat cerebellum. J Neurochem 74:1923-1930.

Li C, Sasaki Y, Takei k, Yamamoto H, Shouji M, Sugiyama Y, Kawakami T, Nakamura F, Yagi Y, Ohshima T, Goshima Y (2004) Correlation between Sema3A-induced facilitation of axonal transport and local activation of a translation initiation factor eIF-4E. J Neurosci 24: 6161-6170.

Li Z, Aizenman CD, Cline HT (2002) Regulation of rho GTPases by crosstalk and neuronal activity in vivo. Neuron 33:741-750.

Luo L, Hensch TK, Ackerman L, Barbel S, Jan LY, Jan YN (1996) Differential effects of the Rac GTPase on Purkinje cell axons and dendritic trunks and spines. Nature 379:837-840.

Marangi PA, Wieland ST, Fuhrer C (2002) Laminin-1 redistributes postsynaptic proteins and requires rapsyn, tyrosine phosphorylation, and Src and Fyn to stably cluster acetylcholine receptors. J Cell Biol 157:883-895.

Martin KC (2004) Local protein synthesis during axon guidance and synaptic plasticity. Curr Opin Neurobiol 14:305-310.

Meng Y, Zhang Y, Tregoubov V, Janus C, Cruz L, Jackson M, Lu WY, MacDonald JF, Wang JY, Falls DL, Jia Z (2002) Abnormal spine morphology and enhanced LTP in LIMK-1 knockout mice. Neuron 35:121-133.

Murai KK, Nguyen LN, Irie F, Yamaguchi Y, Pasquale EB (2003) Control of hippocampal dendritic spine morphology through ephrin-A3/EphA4 signaling. Nat Neurosci 6:153-160.

Nakamura F, Kalb RG, Strittmatter SM (2000) Molecular basis of semaphorin-mediated axon guidance. J Neurobiol 44:219-229.

Nakayama AY, Harms MB, Luo L (2000) Small GTPases Rac and Rho in the maintenance of dendritic spines and branches in hippocampal pyramidal neurons. J Neurosci 20:5329-5338.

Nishiyama M, Hoshino A, Tsai L, Henley JR, Goshima Y, Tessier-Lavigne M, Poo MM, Hong K (2003) Cyclic AMP/GMP-dependent modulation of $\mathrm{Ca}^{2+}$ channels sets the polarity of nerve growth-cone turning. Nature 423:990-995.
Nobes CD, Lauritzen I, Mattei MG, Paris S, Hall A, Chardin P (1998) A new member of the Rho family, Rnd1, promotes disassembly of actin filament structures and loss of cell adhesion. J Cell Biol 141:187-197.

Oinuma I, Ishikawa Y, Katoh H, Negishi M (2004) The Semaphorin 4D receptor Plexin-B1 is a GTPase activating protein for R-Ras. Science 305:862-865.

Okabe S, Kim H-D, Miwa A, Kuriu T, Okada H (1999) Continual remodeling of postsynaptic density and its regulation by synaptic activity. Nat Neurosci 2:804-811.

Okabe S, Miwa A, Okado H (2001) Spine formation and correlated assembly of presynaptic and postsynaptic molecules. J Neurosci 21:6105-6114.

Pasterkamp RJ, Kolodkin AL (2003) Semaphorin junction: making tracks toward neural connectivity. Curr Opin Neurobiol 13:79-89.

Polleux F, Morrow T, Ghosh A (2000) Semaphorin 3A is a chemoattractant for cortical apical dendrites. Nature 404:567-573.

Raper JA (2000) Semaphorins and their receptors in vertebrates and invertebrates. Curr Opin Neurobiol 10:88-94.

Sahay A, Kim CH, Sepkuty JP, Cho E, Huganir RL, Ginty DD, Kolodkin AL (2005) Secreted semaphorins modulate synaptic transmission in the adult hippocampus. J Neurosci 25:3613-3620.

Sasaki Y, Cheng C, Uchida Y, Nakajima O, Ohshima T, Yagi T, Taniguchi M, Nakayama T, Kishida R, Kudo Y, Ohno S, Nakamura F, Goshima Y (2002) Fyn and Cdk5 mediate Semaphorin-3A signaling, which is involved in regulation of dendrite orientation in cerebral cortex. Neuron 35:907-920.

Serini G, Valdembri D, Zanivan S, Morterra G, Burkhardt C, Caccavari F, Zammataro L, Primo L, Tamagnone L, Logan M, Tessier-Lavigne M, Taniguchi M, Puschel AW, Bussolino F (2003) Class 3 semaphorins control vascular morphogenesis by inhibiting integrin function. Nature 424:391-397.

Song H, Ming G, He Z, Lehmann M, McKerracher L, Tessier-Lavigne M, Poo M (1998) Conversion of neuronal growth cone responses from repulsion to attraction by cyclic nucleotides. Science 281:1515-1518.

Takahashi T, Fournier A, Nakamura F, Wang LH, Murakami Y, Kalb RG, Fujisawa H, Strittmatter SM (1999) Plexin-neuropilin-1 complexes form functional semaphorin-3A receptors. Cell 99:59-69.

Takasu MA, Dalva MB, Zigmond RE, Greenberg ME (2002) Modulation of NMDA receptor-dependent calcium influx and gene expression through EphB receptors. Science 295:491-495.

Tamagnone L, Artigiani S, Chen H, He Z, Ming GI, Song H, Chedotal A, Winberg ML, Goodman CS, Poo M, Tessier-Lavigne M, Comoglio PM (1999) Plexins are a large family of receptors for transmembrane, secreted, and GPI-anchored semaphorins in vertebrates. Cell 99:71-80.

Tashiro A, Minden A, Yuste R (2000) Regulation of dendritic spine morphology by the Rho family GTPases: antagonistic roles of Rac and Rho. Cereb Cortex 10:927-938.

Togashi H, Abe K, Mizoguchi A, Takaoka K, Chisaka O, Takeichi M (2002) Cadherin regulates dendritic spine morphogenesis. Neuron 35:77-89.

Toyofuku T, Yoshida J, Sugimoto T, Zhang H, Kumanogoh A, Hori M, Kikutani H (2005) FARP2 triggers signals for Sema3A-mediated axonal repulsion. Nat Neurosci 8:1712-1719.

Uchida Y, Ohshima T, Sasaki Y, Suzuki H, Yanai S, Yamashita N, Nakamura F, Takei K, Ihara Y, Mikoshiba K, Kolattukudy P, Honnorat J, Goshima Y (2005) Semaphorin-3A signaling is mediated via sequential Cdk5 and GSK3 $\beta$ phosphorylation of CRMP2: implication of common phosphorylating mechanism underlying axon guidance and Alzheimer's disease. Genes Cells 10:165-179.

Vaillant AR, Zanassi P, Walsh GS, Aumont A, Alonso A, Miller FD (2002) Signaling mechanisms underlying reversible, activity-dependent dendrite formation. Neuron 34:985-998.

Whitford KL, Marillat V, Stein E, Goodman CS, Tessier-Lavigne M, Chedotal A, Ghosh A (2002) Regulation of cortical dendrite development by SlitRobo interactions. Neuron 33:47-61.

Wong ROL, Ghosh A (2002) Activity-dependent regulation of dendritic growth and patterning. Nat Rev Neurosci 3:803-812.

Yuste R, Bonhoeffer T (2004) Genesis of dendritic spines: insights from ultrastructural and imaging studies. Nat Rev Neurosci 5:24-34.

Zanata SM, Hovatta I, Rohm B, Puschel AW (2002) Antagonistic effects of Rnd1 and RhoD GTPases regulate receptor activity in Semaphorin 3Ainduced cytoskeletal collapse. J Neurosci 22:471-477.

Zhou F-Q, Cohan CS (2004) How actin filaments and microtubules steer growth cones to their targets. J Neurobiol 58:84-91. 